\title{
THE COPULATION OF AMMOPHILA ABBREVIATA
}

\section{By C. H. Turner,}

Sumner High School, St. Louis, Mo.

In the latter part of the summer of 1911, the copulating Ammophilas, illustrated in the accompanying figure, were captured at Merimec Highlands, St. Louis County, Missouri. When first observed they were slowly flying along just above the tops of the four-foot weeds. Occasionally they would touch the tops of the plants; but it was impossible to decide whether such a contact represented a momentary rest or an accidental brushing of the weeds by the wasps. The wasps were captured in a strong cyanide bottle, which killed them immediately. Later a magnified photograph was made of the pair. It is thought that this illustration affords a better idea of the attitude of these wasps during copulation than could be given by a verbal description. The coiled antennæ, the protruding mouthparts, and the general attitude indicate intense excitement. One who believes that insects have emotions will find much in the attitude of these two Ammophilas to support his view.

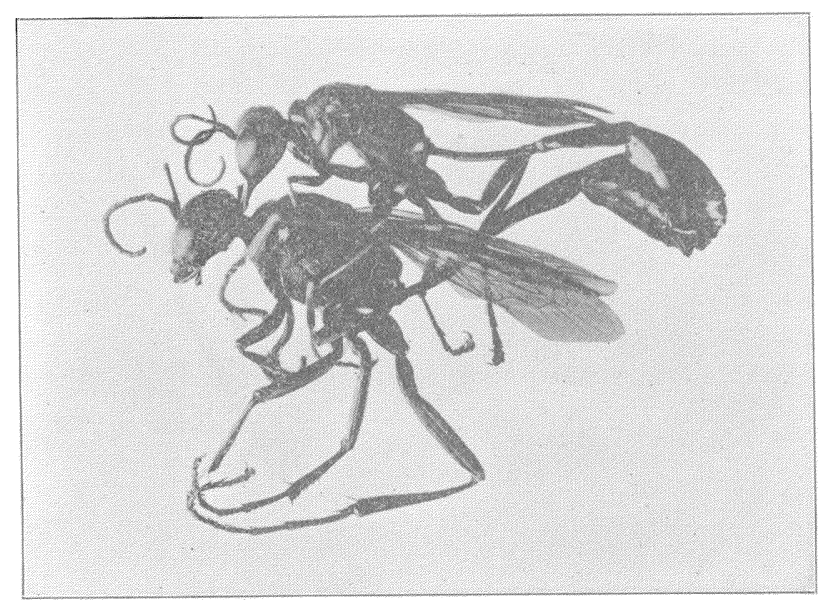

Fig. 1. Ammophila abbreviata Fabr., in copulation. 

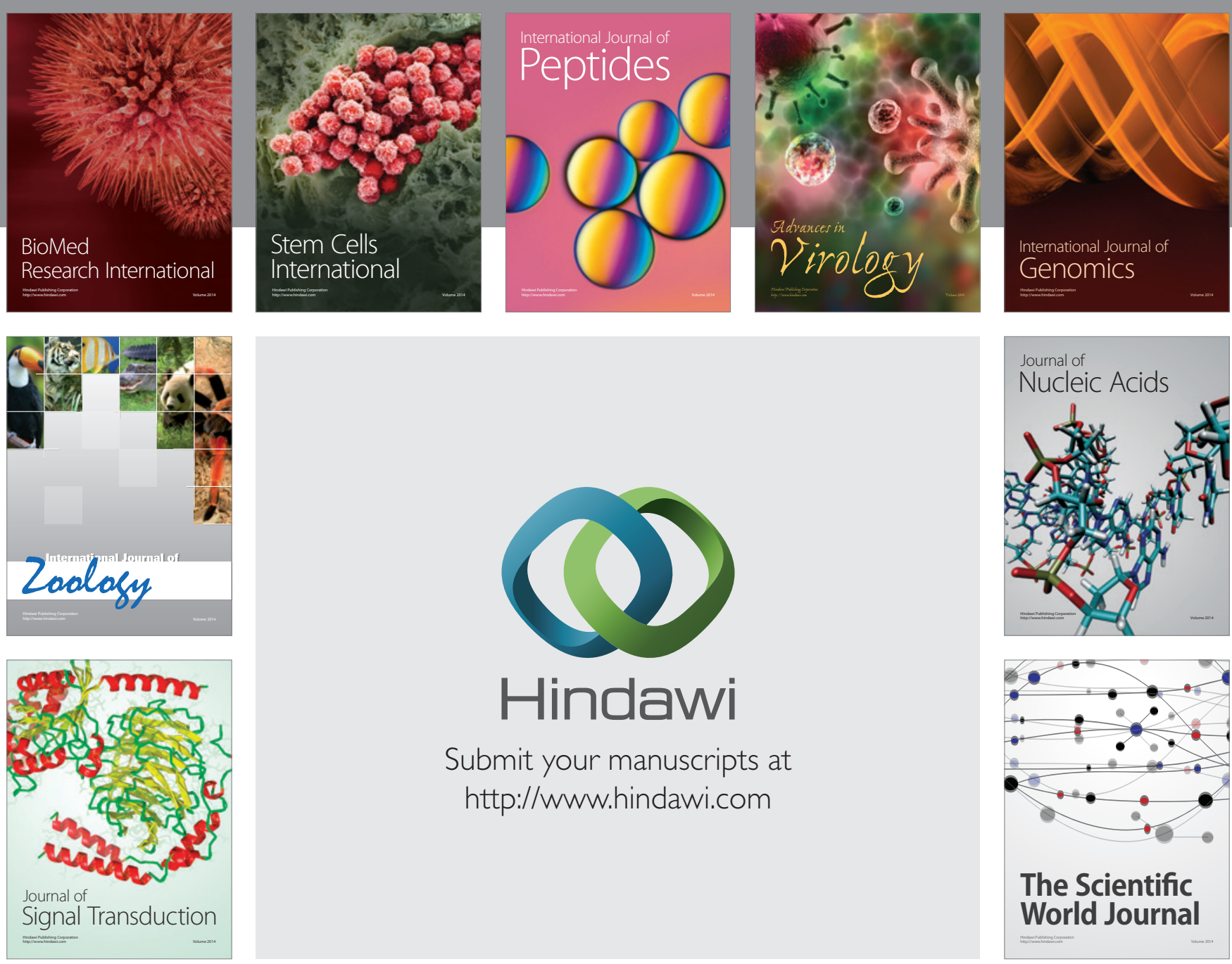

Submit your manuscripts at

http://www.hindawi.com
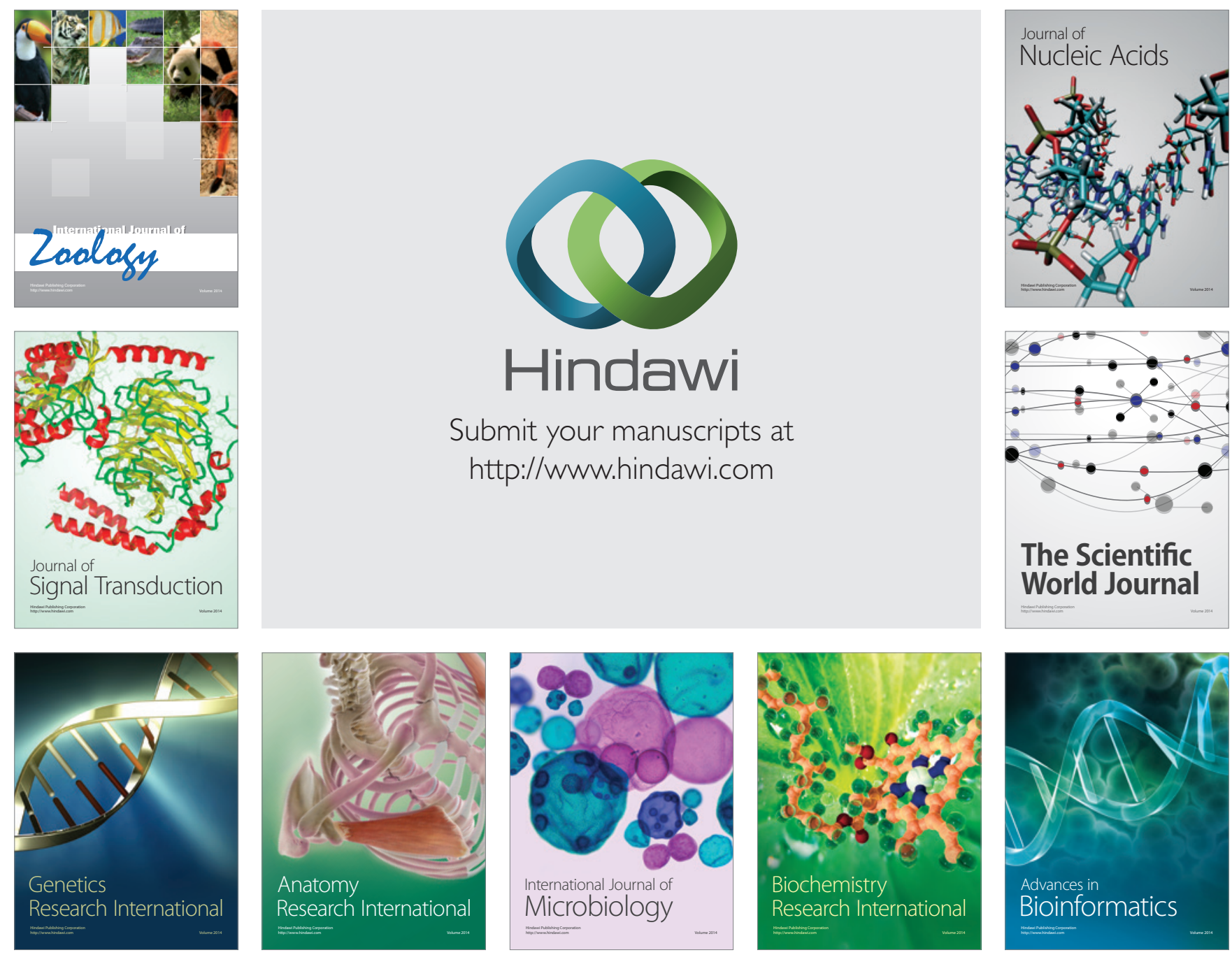

The Scientific World Journal
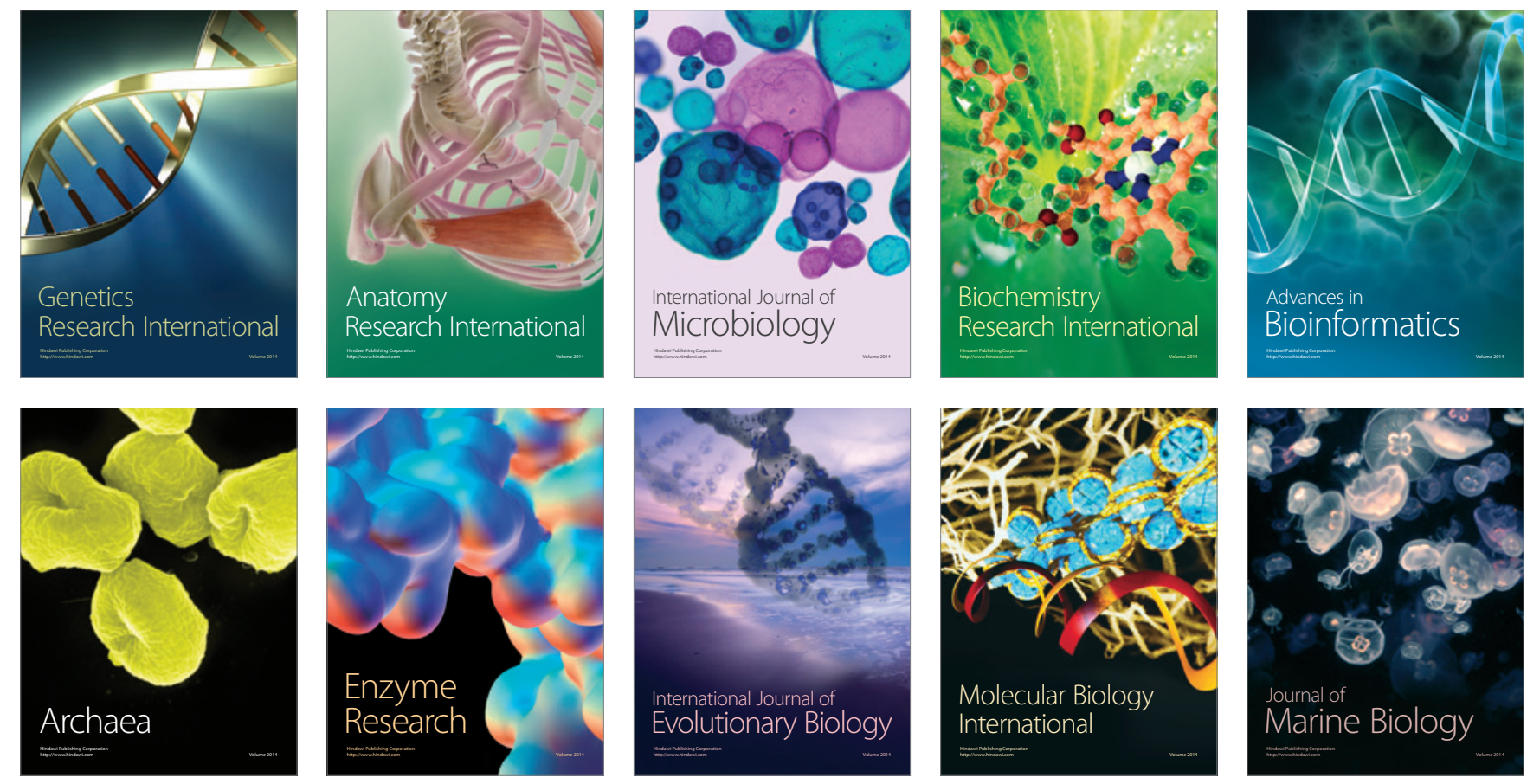